\title{
Novel RNA Markers in Prostate Cancer: Functional Considerations and Clinical Translation
}

\author{
Julia M. A. Pickl, Doreen Heckmann, Leonie Ratz, Sabine M. Klauck, and Holger Sültmann \\ Working Group Cancer Genome Research, German Cancer Research Center (DKFZ) and German Cancer Consortium (DKTK), \\ National Center for Tumor Diseases (NCT), Im Neuenheimer Feld 460, 69120 Heidelberg, Germany \\ Correspondence should be addressed to Holger Sültmann; h.sueltmann@dkfz.de
}

Received 7 March 2014; Revised 1 August 2014; Accepted 5 August 2014; Published 28 August 2014

Academic Editor: Andreas Doll

Copyright (@) 2014 Julia M. A. Pickl et al. This is an open access article distributed under the Creative Commons Attribution License, which permits unrestricted use, distribution, and reproduction in any medium, provided the original work is properly cited.

\begin{abstract}
The availability of ultra-high throughput DNA and RNA sequencing technologies in recent years has led to the identification of numerous novel transcripts, whose functions are unknown as yet. Evidence is accumulating that many of these molecules are deregulated in diseases, including prostate cancer, and potentially represent novel targets for diagnosis and therapy. In particular, functional genomic analysis of microRNA (miRNA) and long noncoding RNA (lncRNA) in cancer is likely to contribute insights into tumor development. Here, we compile recent efforts to catalog differential expression of miRNA and lncRNA in prostate cancer and to understand RNA function in tumor progression. We further highlight technologies for molecular characterization of noncoding RNAs and provide an overview of current activities to exploit them for the diagnosis and therapy of this complex tumor.
\end{abstract}

\section{Introduction}

Prostate cancer $(\mathrm{PCa})$ is the most frequent tumor in men and a major cause of cancer-related morbidity and mortality. The diagnostic application of the prostate specific antigen (PSA) has led to widespread overdiagnosis and subsequent overtreatment of clinically insignificant tumors. This problem will extensively aggravate in the future: with rising life time expectancy, the number of men diagnosed with PCa will increase since the frequency of PCa is steeply rising in elderly men. Thus, there is a huge demand for novel markers for improved PCa diagnosis, prognosis, and therapy decision.

Facilitated by the implementation of ultra-high throughput sequencing technologies, the recent discoveries of the ENCODE consortium (http://encodeproject.org/ENCODE/) confirmed that $80 \%$ of the human genome is transcribed [14]. The GENCODE effort has provided the annotation of more than 9000 lncRNAs [5], as well as micro- (mi-) RNA, small nucleolar (sno) RNA, piwi-interacting (pi) RNA, and others. In parallel, the number of investigations covering the functional analysis of these molecules has increased substantially. Based on these data, it is becoming obvious that many noncoding RNAs are involved in the regulation of gene expression in health and disease, including cancer (Figure 1). For example, global analyses of miRNA expression in cancers revealed robust signatures differentiating between malignant and benign tissues [6], between tumors of several origins, and between primary tumors and metastases [7]. The characterization of miRNA and lncRNA involvement in PCa is likely to result in a better understanding of tumor progression and the identification of novel therapy targets. Here, we provide a summary of recent progress in analyzing noncoding RNA in PCa and in attempting to advance miRNAs and lncRNAs into diagnostic and therapeutic markers.

\section{2. miRNA in Prostate Cancer}

MiRNAs are $20-22$ nt short noncoding RNAs, which regulate gene expression at the posttranscriptional level by mRNA repression and/or degradation. MiRNAs are transcribed as pri-miRNAs by RNA polymerase II (RNA Pol II) and processed by the RNase III enzyme Drosha to generate precursor miRNAs (pre-miRNAs; Figure 1) [8]. Dicer, another RNase III enzyme, then cleaves the pre-miRNA into $\sim 20-22$ long RNA duplexes. Subsequently, the strand with the stable 


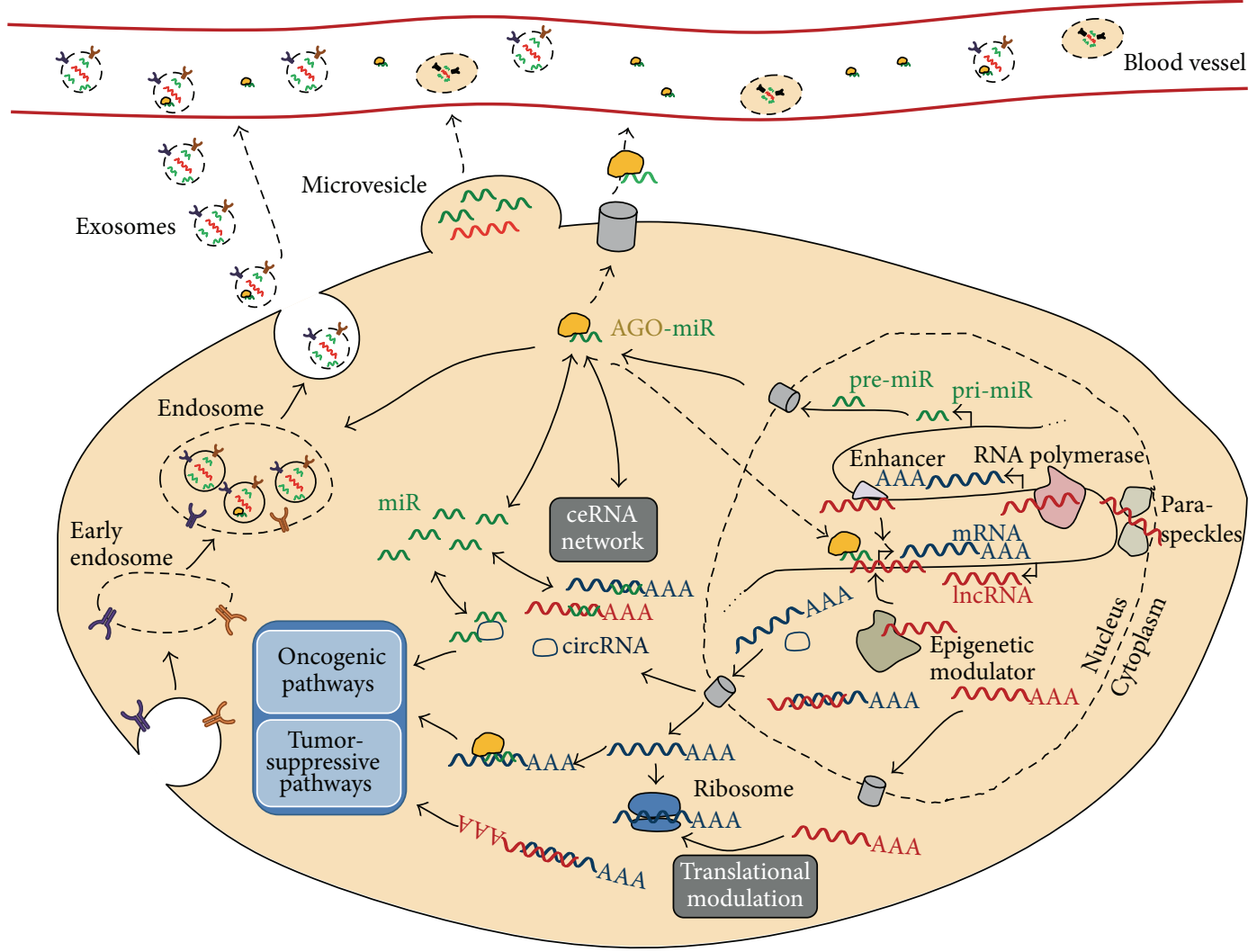

FIGURE 1: Schematic view of functional networks of different RNA species in cancer. Hypothetical interactions are symbolized with dashed arrows. AGO: Argonaute protein (yellow); miR: miRNA (green); lncRNA: long noncoding RNA (red); mRNA: messenger RNA (blue); circRNA: circular RNA (blue).

$5^{\prime}$ end is removed, whereas the complementary strand with the less stable $5^{\prime}$ end is incorporated into Argonaute (AGO) proteins to form the RNA induced silencing complex (RISC). MiRNAs guide the RISC to target mRNAs via sequence complementarity [8-11].

Many miRNAs are known to be deregulated in cancer [6]. For instance, miRNAs are differentially expressed between benign prostate and PCa tissues: in a genomewide microarray-based microRNA expression study, 25 miRNAs were found to be deregulated [12]. Here, $m i R-375$ and $m i R-200 c$ showed highest upregulation in PCa tumor tissue, whereas $m i R-221$ and $m i R-222$ were the most downregulated miRNAs [12]. Using a sequencing-based approach, the same group identified 33 miRNAs being up- or downregulated $>1.5$-fold in PCa tissue [13]. Here, $m i R-143$ and $m i R-145$ were the highest downregulated ones in PCa [13]. Consistent with these data, an independent study found $m i R-145, m i R-221$, and miR-222 among the five most significantly downregulated miRNAs [14], and we identified miR-375 and miR-141 as significantly upregulated in PCa tissue [15].

Other analyses revealed the association of miRNA expression with distinct PCa: for instance, $m i R-375$ expression was reported to be dependent on $\mathrm{pT}$ and $\mathrm{pN}$ status (TNM staging system) of PCa patients, with the highest enrichment in pN1 tumors [16]. Moreover, ten miRNAs (including $m i R-145, m i R-221$, and $m i R-222)$ were downregulated and five (including $m i R-375$ and $m i R-96$ ) upregulated in advanced PCa, whereas miR-96 was associated with tumor recurrence after radical prostatectomy [17]. MiRNAs are also known to correlate with Gleason score: in high-grade $\mathrm{PCa}$, increased expression of $m i R-31, m i R-182$, and $m i R-205$ was identified when compared to intermediate-grade $\mathrm{PCa}$ [18].

The functional consequences of differential expression of various miRNAs have been studied in vitro by many groups. Here, we can address only the most prominent examples: miR-375 was found upregulated in several PCa studies and was known to target Sec23 homolog A (SEC23A) [19], which was involved in trafficking from ER to Golgi [20]. The authors suggested that $m i R-375$-mediated SEC23A downregulation impairs cellular immunogenicity of PCa by reducing HLA class I cell surface receptors [19]. MiR-375 was also shown to downregulate the phosphatase PHLPP2 and to strongly increase prostate carcinoma cell growth [16]. MiR-141, which is upregulated in PCa tissue, was found to downregulate the gene coding for the nuclear receptor subfamily 0 , group $B$, member 2 (NROB2) in prostate epithelial cells. In this way, $m i R-141$ prevented the inhibitory effects of NR0B2 on androgen receptor- $(A R-)$ regulated genes [21]. In contrast, $m i R-143$ and $m i R-145$ were found to be downregulated in $\mathrm{PCa}$ tissue and to be involved in PCa development via regulation of myosin VI (MYO6) [13]. MYO6 was involved in cancer cell dissemination and described as a potential PCa marker $[22,23]$. 
Interestingly, miRNAs, which have not been described as highly deregulated in PCa tissues, were also found to play crucial roles in prostate carcinogenesis. For instance, miR-200b attenuated PCa cell growth and invasiveness [24, $25]$. Studies in the PCa cell line PC-3 suggested that $m i R-200 b$ mediates the reversal of the epithelial-to-mesenchymal transition (EMT) by targeting the prometastatic transcription factors Zinc finger E-box binding homeobox 1 and 2 (ZEB1 and $Z E B 2)$ [25]. Overexpression of $m i R-200 b$ led to increased levels of the epithelial markers E-cadherin, cytokeratins 8 and 18 , as well as downregulation of the mesenchymal markers fibronectin and vimentin $[25,26]$. Another study found $m i R-1$ to be reduced with $\mathrm{PCa}$ progression. SLUG is a regulator of mesenchymal differentiation and was assumed to repress $m i R-1$ and $m i R-200$ transcription whereas $m i R-1$ and $m i R-200$ are also able to regulate $S L U G$ by a mutually inhibitory feedforward loop [27]. Moreover, $m i R-1$ was found to act as a mediator of oncogenic pathways in the PCa cell lines PC-3 and LNCaP: the heat-shock protein HSPB1 reduced miR-1 levels leading to an activation of AR and TGFB1 signaling cascades [28].

MiRNAs are also able to regulate the expression of important epigenetic marker genes. For instance, miR-34b targeted methyltransferases and deacetylases in PCa [29]. $M i R-34 b$ is also an example for epigenetic miRNA regulation via a positive feedback loop. MiR-34b was found to directly target the AKT pathway like $A K T$ itself and its downstream genes GSK3B, CTNNB1, MYC, and CCND1, which were involved in cell proliferation and survival [29]. In a PCa xenograft model, miR-34b exhibited antitumor properties by decreasing prostate tumor growth [29]. This was probably due to affecting EMT since miR-34b expression decreased the mesenchymal markers vimentin, ZO1, $\mathrm{N}$-cadherin, and SNAIL, and increased E-cadherin [29]. Furthermore, $m i R-152$ was reported to downregulate DNA (cytosine-5)-methyltransferase 1 (DNMT1) in LNCaP, PC-3, and MDA-PCa-2b cells. DNMT1 siRNA caused an increase of $m i R-152$ expression, suggesting a reciprocal relationship between DNMT1 and $m i R-152$. Increased DNMT1 and depletion of $m i R-152$ were assumed to arise during the progression to advanced PCa [30]. The $m i R-200$ family was downregulated by the histone methyltransferase enhancer of zeste homolog 2 (EZH2) [24]. EZH2 is a component of the polycomb repressive complex 2 (PRC2), which is involved in epigenetic regulation of cell homeostasis. EZH2 expression was elevated in aggressive forms of PCa [31]. MiR-200 family on the other hand represses PRC1 proteins BMI1 and RING2. Therefore, increased PRC2 levels lead to an increase of PRC1 expression due to miRNA linkage, suggesting crucial roles for miRNA in regulating the epigenetic silencing machinery [24].

MiRNAs are primarily known as key regulators of active genes. However, it has recently been shown that the expression of the PTEN pseudogene (PTENP1) is able to rescue the expression levels of its ancestral gene PTEN by competing for the same set of miRNAs ( $m i R-20 a, m i R-19 b, m i R-21, m i R-26 a$, and $m i R-214$ ) [32]. Similarly, the pseudogene KRASP1 derepressed KRAS in DU145 cells, probably by sharing common sites for $m i R-143$ and let-7 [32]. Thus, expressed pseudogenes can display tumor suppressive or oncogenic properties by acting as competitive endogenous RNAs (ceRNAs) for their corresponding active genes: the increased number of miRNA binding sites upon pseudogene expression was able to titrate the pool of available miRNAs in PCa cells, and miRNA concentrations are regulated by the abundances of their target genes. In this concept, target RNAs are not only passive substrates of miRNAs but also active players in the regulatory networks leading to PCa progression.

The identification of their target genes is essential to estimate the potential of miRNAs as biomarkers. Many bioinformatic tools are able to predict miRNA target genes (Table 1). However, since these tools are based on certain assumptions (e.g., base complementarity in the $3^{\prime} \mathrm{UTR}$, thermodynamic stability, target-site accessibility, and evolutionary conservation of miRNA binding sites), their predictions are accompanied by large numbers of false positives. Thus, experimental approaches for targetome identification in vitro are required. For example, using AGO-RNA immunoprecipitation, followed by sequencing (AGO-RIP-Seq) AGO2/miRNA/RNA target complexes are captured from cells stably expressing a miRNA of interest. MiRNA-associated targets are then identified and quantified by deep transcriptome sequencing. AGO-RIP-Seq also enables the identification of novel nonannotated RNA targets like lncRNAs or pseudogenes. Other methods (AGO-HITS-CLIP [33, 34], AGO-PAR-CLIP [35], and $C L A S H$ [36]) use crosslinking of the AGO complex to obtain more information about miRNA binding to target genes. These techniques have revealed that some miRNAs can also bind their targets in the coding regions of genes and that other miRNAs do not require base complementarity at all in order to regulate target gene expression [33-36]. These methods are rather novel, and systematic studies reporting the experimental analysis of genomewide miRNA targetomes in PCa have not been described to the best of our knowledge.

MiRNAs are also known to be present in the nucleus [37-40]. Nuclear miRNAs are considered as regulators of gene expression at the transcriptional level (reviewed in [41]). For instance, miRNAs are supposed to bind to promoter sequences in an AGO-dependent manner to regulate gene transcription in the PCa cell line PC-3. This hypothesis was supported by the finding that AGO1-bound promoter sequences contain putative miRNA binding sites [39] and suggest a role for miRNAs in PCa not only in the cytoplasm, but also in the nucleus.

\section{Long Noncoding RNA in Prostate Cancer}

Long noncoding RNAs (lncRNAs) are defined by their length, which ranges from 200 bases up to $100 \mathrm{~kb}$. LncRNAs have adopted the transcriptional machinery from proteincoding genes (Figure 1): they are primarily transcribed by RNA Pol II, frequently contain a $5^{\prime}$ terminal methylguanosine cap, and are often spliced and polyadenylated [42]. However, a set of nonpolyadenylated lncRNAs has also been identified to be transcribed from RNA polymerase III promoters $[43,44]$. The fact that lncRNAs have been found to bind to ribosomes raises the possibility that they are potentially translatable into proteins. Indeed, ribosome profiling [45] 


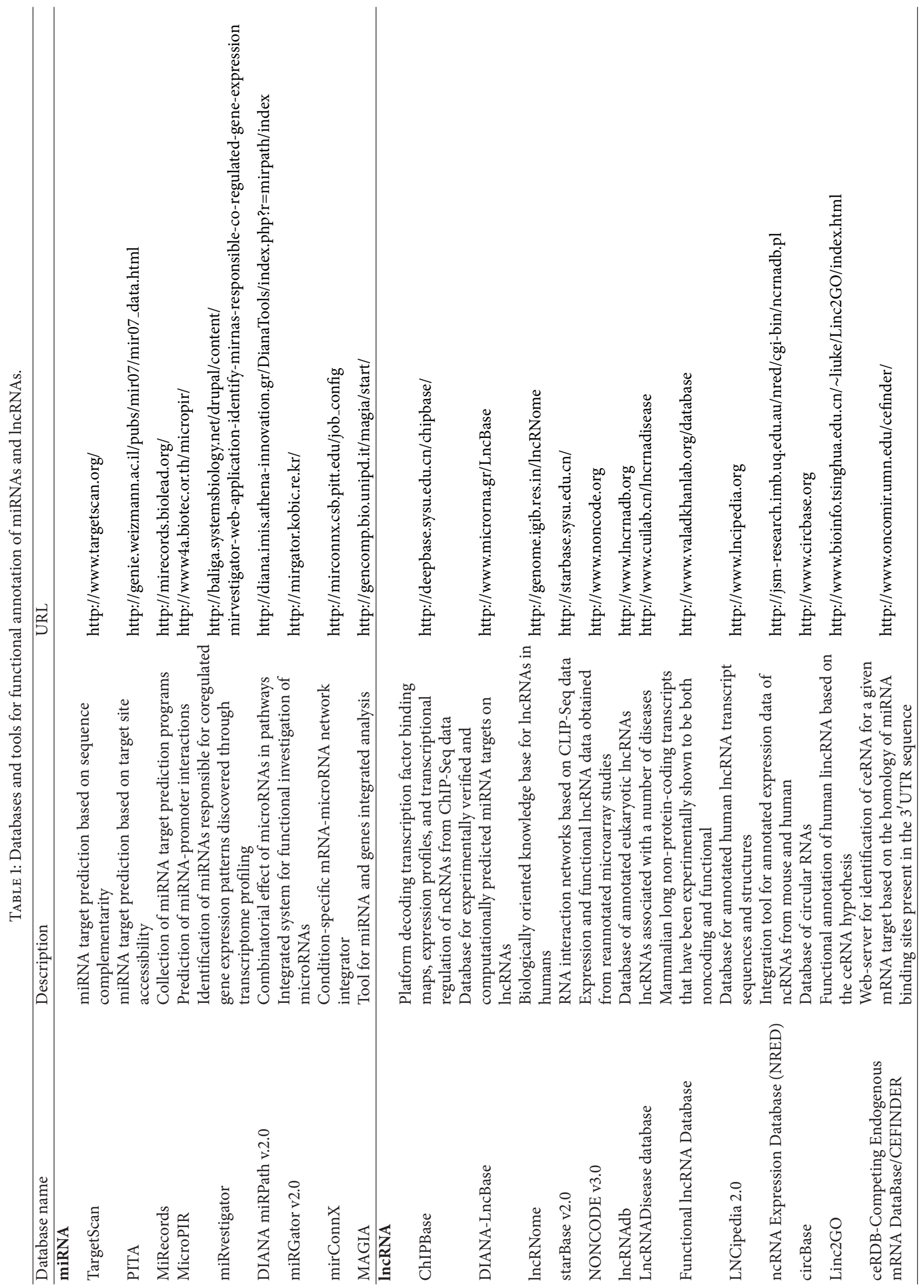


and mass spectrometry approaches [46] detected small peptides potentially derived from lncRNAs. However, the lack of conserved long open reading frames supports the idea that lncRNAs do not encode proteins but rather exert regulatory functions. LncRNAs are cataloged according to their genomic localization: long intergenic noncoding RNAs (lincRNAs) are derived from regions that are devoid of other genes, whereas intronic $\ln c R N A s$ are transcribed from introns of protein coding genes. LncRNAs originating from opposite strands of the same genomic locus are called sense/antisense pairs and are divided into convergent (head-to-head), divergent (tail-to-tail), and fully overlapping transcripts [47]. LncRNAs are expressed at much lower levels and with much higher cell-type specificity than mRNAs [5]. Although lncRNAs are observed in many species, their degrees of evolutionary conservation are low, and some of the human lncRNAs are thought to have arisen solely in primates [5].

In $\mathrm{PCa}$, the most prominent and clinically relevant RNA biomarker is the antisense lncRNA PCA3, which is overexpressed in $>95 \%$ of primary tumors [48]. PCA3 is a diagnostic biomarker detectable in urine [49], with higher specificity compared to PSA [50]. One of the first lncRNAs suggested as a marker for PCa incidence, androgen-dependent proliferation, and antiapoptotic signaling in cell lines was the PCa gene expression marker 1 (PCGEM1) [51-54]. Overexpression of PCGEM1 in tumor cells inhibited PARP (poly-ADP-ribosepolymerase) cleavage and delayed the induction of p53 and p21 [52], resulting in increased chemoresistance. PCGEM1 was found to bind to AR at methylated K349 and to regulate the expression of AR target genes, which stimulated tumor growth in a PCa xenograft mouse model [54]. Additionally, two single-nucleotide polymorphisms (SNP) contributing to cancer risk were identified in PCGEM1 [55].

In a more recent and comprehensive study, Prensner and colleagues, by analyzing the transcriptomes of 102 prostate tumors and cell lines using next generation sequencing [56], identified 121 so far nonannotated PCa-associated noncoding RNA transcripts (PCATs). PCAT-1 was upregulated in a subset of metastatic and high-grade localized prostate tumors. PCAT-1, a transcriptional target of EZH2, stimulated cell proliferation [56] and impaired homologous recombination by repressing of the BRCA2 gene [57]. PCa noncoding RNA 1 (PRNCR1; PCAT-8), which is located immediately adjacent to PCAT-1 and the $c-M Y C$ oncogene at the wellknown PCa risk locus on chromosome 8q24 [58, 59], was identified to be upregulated in aggressive prostate tumors [54]. PRNCR1-bound DOT1-like histone H3K79 methyltransferase (DOT1L) methylated the AR at position K349, which mediated the interaction of AR with PCGEM1, thereby resulting in ligand-independent activation of AR signaling and cell proliferation [54]. PCAT-18 was recently suggested as a biomarker for metastatic PCa [60]. Knockdown of PCAT-18 decreased cell proliferation, migration, and invasion but also triggered apoptosis by promoting caspase activity [60]. In another study, PCAT-114 (SCHLAP1) expression correlated with high-grade, metastatic PCa (see below). By analyzing the transcriptomes of 14 prostate tumors and adjacent benign tissues in another genomewide approach, 137 new lncRNAs were identified [61]. One of these, the metastasis associated in lung adenocarcinoma transcript 1 (MALAT-1), was suggested to be a novel marker for PCa diagnosis [62]: high expression of MALAT-1 correlated with high Gleason score, PSA, tumor stage, and castration-resistant PCa (CRPC).

The majority of PCa are driven by androgen signaling. Various studies have highlighted the functions of androgenresponsive or AR-interacting lncRNAs: Takayama and colleagues identified the antisense lncRNA C-terminal binding protein (CTBP1-AS) as highly upregulated in PCa, by repressing its sense gene $C T B P 1$, an AR corepressor. This is achieved by recruitment of the transcriptional repressor SFPQ (splicing factor proline/glutamine-rich) and histone deacetylases to the promoter of CTBP1 [63], thereby promoting androgendependent and castration-resistant tumor growth [63]. The PCa-upregulated lncRNA PlncRNA-1 modulates apoptosis and proliferation through regulation of the AR [64]. Recently, PCAT-29 was identified as an androgen-repressed suppressor of growth and metastases of prostate tumors [65]. The same group contradicted the prognostic value of PCGEM1 and PRNCR1 in aggressive PCa [54]: in a large high-risk PCa patient cohort, Prensner and colleagues could not find any evidence for the binding of these lncRNAs to the AR [66].

As lncRNAs do not encode proteins, their functions are closely associated with their abundance. Bioinformatic tools such as the "guilt by association analysis" [67] are capable of predicting the function of an lncRNA. This method uses coexpression analysis of lncRNAs with protein coding genes in signaling pathways to predict the functions of the lncRNAs. This approach has led to the prediction of various roles for lncRNAs, ranging from stem cell pluripotency to cancer [42]. Besides such bioinformatic approaches and databases listing annotated lncRNAs and functional assignment (Table 1), several crosslinking methodologies have been developed to experimentally elucidate the interactomes of lncRNAs in vitro. Chromatin isolation with RNA purification (ChIRP) [68] and capture analysis of RNA targets (CHART) [69] are able to copurify lncRNA-bound proteins and DNA in juxtaposition. In DHT- (dihydrotestosterone-) stimulated LNCaP PCa cells, ChIRP uncovered thousands of PCGEM1 occupancy sites, colocalizing with ARE and H3K4mel-marked enhancers [54].

The regulatory potential of lncRNAs, in particular lincRNAs, has been best characterized in the context of their roles as epigenetic modulators. It was observed that $20 \%$ of cellular lncRNAs are associated with specific chromatin modification complexes, such as PRC2, which mediates histone $\mathrm{H} 3$ lysine 27 trimethylation (H3K27me3) [70, 71]. ANRIL, an lncRNA overexpressed in $\mathrm{PCa}$, mediated epigenetic silencing of the adjacent tumor suppressor $p 15$ via $\mathrm{H} 3 \mathrm{~K} 27$ trimethylation of the CDKN2A (INK4A/ARF) locus by directly interacting with SUZ12, a component of PRC2, and CBX7, a PRC1-associated chromodomain-containing protein [72, 73]. In aggressive $\mathrm{PCa}$, aberrantly high expression of PCAT-114 inhibited SWI/SNF-mediated epigenetic regulation, due to direct disruption of SNF5 activity, a core unit of the SWI/SNF complex [74]. As it has been shown that the expression of PCa-associated lncRNAs can be regulated by long terminal repeats (LTRs) [75], PCAT-114 might be regulated through an LTR in its $5^{\prime}$ UTR (own unpublished observations). 
Currently, there is little evidence for a direct interaction between lncRNAs and DNA [68]. In contrast, the crosstalk of IncRNA with other RNA species has been studied in detail $[35,76]$. Antisense lncRNAs can regulate the stability and translation of complementary mRNAs. For example, translation of the UCHL1 mRNA was found to be regulated by its antisense lncRNA through complementary $5^{\prime}$ overlap and an embedded inverted SINEB2 element [77]. In another example, imperfect base pairing between Alu elements in lncRNAs and the $3^{\prime}$ UTR of translationally active mRNAs resulted in a double-stranded RNA, which is bound by staufen double-stranded RNA binding protein 1 (STAU1) and subsequently targeted for degradation [78].

The ceRNA concept [32] also suggests that lncRNAs-like mRNAs-act as natural sponges (Figure 1). In this context, a long noncoding circular RNA (circRNA) was identified to harbor more than 70 target sites for $m i R-7$. Binding of this miRNA to the sponge circRNA suppressed miRNA activity, resulting in miRNA target derepression $[79,80]$. CircRNA datasets are publically available via http://www.circbase.org/ (Table 1).

The noncoding part of the human genome offers comprehensive prospects to identify the genetic factors and mechanisms, which are critical for PCa initiation, development, and progression. However, a recent study suggests that a particular lncRNA may exert both oncogenic and tumorsuppressive functions in PCa [81]. This indicates that lncRNA action is highly context-dependent, and further efforts are required to understand the increasing complexity of lncRNA function in health and disease.

\section{PCa Diagnosis and Treatment Monitoring Using Circulating RNA Markers}

The remarkable stability of noncoding RNAs prompted efforts to evaluate their potential as diagnostic or prognostic molecular markers. In particular, genetic material released from tumor cells into the blood or other body fluids ("liquid biopsy") could provide a rich source of such markers that can be exploited to gain insights into the molecular alterations associated with disease progression [82]. In PCa, liquid biopsies could be highly valuable since the heterogeneity of the tumors often precludes precise staging and grading. In addition, a faithful representation of tumor aggressiveness in easily accessible liquids could lead to an improved therapy decision.

MiRNAs circulating freely in blood have been studied as potential biomarkers for PCa [83, 84]. Several miRNAs were demonstrated to discriminate between $\mathrm{PCa}$ and healthy controls or patients with benign prostate hyperplasia $(\mathrm{BPH})$ $[83,85]$, as well as between localized and metastatic PCa [86]. Brase et al. observed an overall higher level of circulating miRNAs in serum samples of patients with advanced PCa compared to those with primary PCa [15]. Of 667 miRNAs screened, 69 miRNAs were found to be more abundant in sera of lymph-node positive versus negative PCa patients. MiR-375 and miR-141 showed statistically significant correlation with clinical patient parameters and were identified as the best serum markers for aggressive PCa [15]. Significantly higher abundance of $m i R-141$ in localized PCa compared to metastatic disease in plasma samples was also seen by other groups $[87,88]$, while $m i R-21$ distinguished best between early-stage disease and healthy controls and was correlated with resistance to docetaxel [89]. Serum miR-194 correlated with biochemical recurrence and poor prognosis [88]. The first clinical studies are ongoing which examine the benefit of circulating miRNAs for PCa diagnosis and disease monitoring (Table 2). These include investigations to determine whether specific miRNA profiles are related to PCa outcome in high-risk PCa patients as well as screening studies for novel markers (including miRNA and IncRNA) associated with tumor progression in general (e.g., http://www.mdanderson.org/) or with locally recurrent or metastatic PCa. Furthermore, the potential of circulating miRNA markers as tools for companion diagnostics in clinical trials (prediction of therapy response against abiraterone or combination therapies; Table 2) is currently being explored.

Two recent studies suggested the detection of transcript levels of selected mRNAs in whole-blood samples of patients with CRPC as useful prognostic markers [90, 91]: a panel consisting of six circulating $m R N A$ markers (ABL2, C1QA, SEMA4D, TIMP1, ITGAL, and CDKN1A) predicted survival when compared to clinical and histopathological parameters of prognostic significance in CRPC [91]. Poor prognosis and poor overall survival of patients with CRPC were correlated with a nine-gene model (RHAG, CA1, HEPACAM2, SNCA, HEMGN, SOX6, TMEM56, OSBP2, and RHD) [90]. The determination of $P C A 3$ in peripheral blood in combination with increased PSA level $(>10 \mathrm{ng} / \mathrm{mL})$ showed high specificity and improved diagnostic accuracy to distinguish $\mathrm{BPH}$ from PCa [92]. Since PCa often carries genomic rearrangements involving androgen-regulated genes, the role of rearrangement-associated biomarkers could also be exploited for diagnostic purposes. Urine-based combined detection of PCA3 and TMPRSS2:ERG DNA was used for improved risk stratification of men with elevated serum PSA levels to guide further disease management [93], and changes in PCA3 and TMPRSS2:ERG levels are currently used as marker to evaluate the effect of treatment with the gonadotropinreleasing hormone agonist Triptorelin (Decapeptyl) in a Phase III multicenter study in patients with advanced PCa (NCT01020448; https://clinicaltrials.gov/). A multiplex marker panel consisting of PCA3, TMPRSS2:ERG, annexin A3, sarcosine, and serum PSA showed improved diagnostic accuracy for PCa [94].

Circulating miRNAs have been found to be present in microvesicles such as exosomes (Figure 1). Exosomes are nanosized $(40-100 \mathrm{~nm})$ extracellular vesicles secreted from cells via the endosomal pathway. Tumor cells release exosomes at increased levels, which are then detectable in different body fluids. Exosomal miRNAs reflect the miRNA signature of the tumor, and differences in miRNA content and expression were found in exosomes derived from cancerous versus noncancerous cell lines and in tumor-derived exosomes compared to those from healthy individuals [95-97]: in PC-3 cell lines, miRNA profiling identified 31 miRNAs that were 
TABLE 2: MiRNA-based biomarker studies in prostate cancer.

\begin{tabular}{|c|c|c|c|c|}
\hline Trial title & Objectives & Study type & Source & Trial number \\
\hline $\begin{array}{l}\text { Micro-RNA Expression Profiles } \\
\text { in High Risk Prostate Cancer }\end{array}$ & $\begin{array}{l}\text { Correlation of miRNA } \\
\text { expression with prostate } \\
\text { cancer outcome }\end{array}$ & $\begin{array}{l}\text { Observational } \\
\text { retrospective }\end{array}$ & Radical prostatectomy & NCT01220427 \\
\hline $\begin{array}{l}\text { Blood and Tissue Samples From } \\
\text { Patients with Locally Recurrent } \\
\text { or Metastatic Prostate Cancer }\end{array}$ & $\begin{array}{l}\text { Sequencing of genomic } \\
\text { tumor DNA, genotyping, } \\
\text { gene expression, and } \\
\text { miRNA/noncoding RNA }\end{array}$ & $\begin{array}{l}\text { Observational } \\
\text { prospective }\end{array}$ & $\begin{array}{l}\text { Blood, soft tissue or bone } \\
\text { metastases }\end{array}$ & NCT01050504 \\
\hline $\begin{array}{l}\text { MicroRNA in Prostate Cancer } \\
\text { Progression: Genetic Variation, } \\
\text { Genotype-Phenotype Correlation, } \\
\text { and Circulating Biomarker }\end{array}$ & $\begin{array}{l}\text { MiRNAs as predictors of } \\
\text { progression }\end{array}$ & Biomarker screening & $\begin{array}{l}\text { Tumor versus normal } \\
\text { tissue, plasma }\end{array}$ & $\begin{array}{l}\text { MD Anderson } \\
\text { Cancer Center }^{\mathrm{b}}\end{array}$ \\
\hline $\begin{array}{l}\text { Abiraterone Acetate in Treating } \\
\text { Patients with Metastatic } \\
\text { Hormone-Resistant Prostate } \\
\text { Cancer }\end{array}$ & $\begin{array}{l}\text { MiRNA expression in } \\
\text { tumor metastases as } \\
\text { biomarker for sensitivity } \\
\text { and resistance; correlation } \\
\text { of miRNA with response } \\
\text { and progression }\end{array}$ & $\begin{array}{l}\text { Interventional, Phase II } \\
\text { clinical trial }\end{array}$ & Blood (biopsy) & NCT01503229 \\
\hline $\begin{array}{l}\text { Bicalutamide and Goserelin or } \\
\text { Leuprolide Acetate w/wo } \\
\text { Cixutumumab in Patients with } \\
\text { Newly Diagnosed Metastatic } \\
\text { Prostate Cancer }\end{array}$ & $\begin{array}{l}\text { Correlation of miRNA } \\
\text { expression and CTC } \\
\text { count }\end{array}$ & $\begin{array}{l}\text { Interventional, Phase II } \\
\text { clinical trial }\end{array}$ & Serum & NCT01120236 ${ }^{\mathrm{a}}$ \\
\hline
\end{tabular}

${ }^{a}$ http://clinicaltrials.gov.

${ }^{b}$ http://www.mdanderson.org.

exclusively present in exosomes [96]. In larger extracellular vesicles (>200 nm), $m i R-141, m i R-375$, and $m i R-205$, known to be associated with PCa progression, and miR-31 (which targets AR) were differentially expressed [97]. So far, there are only few reports analyzing miRNAs in microvesicles derived from PCa patients. However, a recent study found differential expression of eleven miRNAs, of which miR-107 exhibited the largest differential expression in circulating microvesicles from PCa patients compared to controls [86]. Additionally, 16 miRNAs were found to be enriched in microvesicles of patients with metastatic PCa compared to patients with organ-confined disease [86]. In this study, $m i R-375$ and $m i R-141$ were significantly enriched in plasmaderived microvesicles from patients with metastatic disease. Exosomal TMPRSS2:ERG and PCA3 mRNA from urine samples of untreated PCa patients have also been proposed as a potential diagnostic test [98].

All exosomal content is derived from their parental cells. However, the precise mechanism of miRNA/lncRNA/protein delivery into exosomes is not fully understood. Notably, the RNA and protein cargo within exosomes was shown to be functionally active in recipient cells, which suggests that tumor cells can exploit circulating exosomes as a means to "communicate" with their regional or distal environment $[95,99,100]$.

\section{Preclinical Studies for ncRNA-Based PCa Therapy}

With the identification of PCa-specific miRNA expression patterns and the understanding of their role in PCa biology, novel opportunities for miRNA-based therapies arise. These include targeting the $3^{\prime}$ UTRs of oncogenes using specific miRNAs, restoring normal intracellular miRNA pools, or enhancing therapeutic response by combining miRNA with existing anticancer drugs, attempting to exploit the concept of synthetic lethality. In this section, we highlight in vivo studies that support the implementation of miRNA-based therapeutics (Table 3 ).

The ability of let-7 to inhibit tumor initiation was first demonstrated in a murine CD44-positive xenograft model, where overexpression and therapeutic injection of let-7 resulted in delayed tumor formation [101-103]. Intratumoral administration of $m i R-199 a-3 p$ mimics into a murine $\mathrm{PCa}$ xenograft model led to decreased expression of the oncogene Aurora kinase A (AurkA), which is associated with a malignant PCa phenotype [104]. In another murine xenograft model, using transfected PCa cell lines [103], miR-128 showed antiproliferative as well as proapoptotic effects and negatively regulated PCa stem cells by directly targeting the stem cell related genes Bmi-1 and Nanog (Nanog homeobox). Additionally, clonogenic and tumorigenic properties of $\mathrm{PCa}$ cells were inhibited in a dose-dependent manner by different levels of endogenous miR-128. MiR-16 replacement therapy in a luciferase PCa xenograft substantially reduced bone metastatic tumor growth compared to untreated mice [105]. MiR-26a, which is downregulated in PCa, was shown to inhibit growth and metastatic progression of human-tumor xenografts, probably by targeting lin-28 homolog B ( Lin28B) and zinc finger $\mathrm{CCHC}$ domain containing 11 (ZCCHC11) [106]. Finally, downregulation of the lncRNA MALAT-1 
TABLE 3: MiRNA-based therapeutics in prostate cancer preclinical trials.

\begin{tabular}{llllll}
\hline miRNA & Target & Model used & Delivery method & Phenotypes & Reference \\
\hline Let-7 & Myc, RAS & $\begin{array}{l}\text { AR-negative mouse } \\
\text { xenograft }\end{array}$ & $\begin{array}{l}\text { Let-7c-lentivirus } \\
\text { intratumoral injection }\end{array}$ & Repressed tumor growth & Nadiminty et al. [102] \\
\hline miR-199a-3p & $\begin{array}{l}\text { Aurora } \\
\text { kinase A }\end{array}$ & DU145 mouse xenograft & $\begin{array}{l}\text { Agomir intratumoral } \\
\text { injection }\end{array}$ & Reduced tumor growth & Qu et al. [104] \\
\hline miR-16 & CDK1, & $\begin{array}{l}\text { Murine bone metastatic } \\
\text { prostate cancer model }\end{array}$ & Intravenous injections & $\begin{array}{l}\text { Reduced tumor } \\
\text { development in bone tissue }\end{array}$ & Takeshita et al. [105] \\
\hline miR-34a & CD44, & CD44 mouse xenograft & $\begin{array}{l}\text { Intratumoral and systemic } \\
\text { injection of miR-34a oligo }\end{array}$ & $\begin{array}{l}\text { Reduced tumor volume and } \\
\text { lung metastasis, prolonged } \\
\text { survival }\end{array}$ & Liu et al. [107] \\
\hline miR-221 & p27 & PC-3 mouse xenograft & $\begin{array}{l}\text { Intratumoral injections of } \\
\text { miR-221/miR-222 } \\
\text { antagomirs }\end{array}$ & Reduced tumor growth & Mercatelli et al. [110] \\
\hline
\end{tabular}

delayed tumor growth in vivo and reduced metastasis of $\mathrm{PCa}$ xenografts in castrated male nude mice [62].

Intratumoral and systemic injection of $m i R-34 a$ into mice grafted with human PCa tumors resulted in reduced tumor volumes and lung metastasis and was associated with prolonged survival by suppressing the adhesion molecule CD44 [107]. Deregulated $m i R-34 a$ expression was also linked to drug resistance, showing a sevenfold decrease in paclitaxelresistant PC-3 cells compared to wild-type PC-3 cells [108]. Overexpression of $m i R-34 a$ in paclitaxel-resistant PC-3 cells recovered paclitaxel sensitivity, while $m i R-34 a$ antagomir transfection attenuated it [108].

Liu et al. [107] and Kojima et al. [108] presented a rationale for $m i R$-34a-based therapy to target PCa stem cells and drugresistant PCa. MiR-34a has emerged as therapeutical agent under the name MRX34, a liposome-encapsulated miR-34 mimic (http://www.mirnatherapeutics.com) and is currently being studied in a multicenter Phase I clinical trial in patients with unresectable primary liver cancer and liver metastases derived from tumors of other primary origin (NCT01829971; https://clinicaltrials.gov/).

Restoration of $m i R-30 b$ expression by src tyrosine kinase (Src) inhibitors was able to prolong survival and reduce metastatic disease of VCaP-derived xenograft mice by negatively regulating TMPRSS2:ERG and downregulating EMTassociated as well as ERG target genes [109]. Consequently, inhibitors of the AR activator Src are currently being tested in Phase I and II clinical trials for the treatment of PCa patients. Similar to the reconstitution of silenced miRNAs, suppression of overexpressed miRNAs was also shown to be a potential therapeutic approach: Mercatelli et al. established an antagomir targeting $m i R-221$ [110]. Inverse correlation of $m i R-221$ and p27 protein level was validated in primary cells from 18 patients with stage II-III PCa. In mouse xenograft models, intratumoral injection of a $m i R-221$ antagomir led to significantly reduced tumor growth, which was correlated with p27 upregulation [110].

There are currently no clinical trials studying miRNAs as therapeutics in human PCa. However, the data from these and other preclinical in vivo models using miRNAbased therapeutic approaches provide promising results for potential future applications in human PCa.

\section{Summary}

The advent of ultra-high throughput sequencing technologies has caused a vast expansion of the catalog of noncoding RNA molecules. Thus, on the one hand, we are closer to an overview of the transcriptional landscapes in health and disease. On the other hand, the complexity of regulatory factors has grown substantially, and we have just started to uncover some underlying principles: although miRNAs are probably the best investigated class of noncoding RNAs, the recent discoveries of complex miRNA and ceRNA networks and nuclear miRNAs indicate that our understanding of miRNAs in PCa progression is far from complete. Similarly, the analysis of lncRNAs has just commenced, and the roles of the majority of PCATs and other lncRNAs in PCa remain to be investigated. The reports on novel diagnostic PCa biomarkers from liquid biopsies are encouraging. However, the data are mostly based on discovery-driven approaches that frequently have limited validity due to small sample sizes, nonstandardized settings, and different experimental designs. Thus, the diagnostic and therapeutic benefits of many potential RNA markers in PCa still need to be proven in well-controlled and standardized large-scale prospective clinical studies.
Abbreviations
BPH: CeRNA:
Benign prostate hyperplasia
CHART:
Competitive endogenous RNA
ChIP:
Capture analysis of RNA targets
ChIRP: Chromatin immunoprecipitation
circRNA: Circur RNA
CLASH: Crosslinking, ligation, and sequencing of hybrids
CRPC: $\quad$ Castration-resistant prostate cancer
DHT: Dihydrotestosterone
EMT: $\quad$ Epithelial-to-mesenchymal transition
HITS-CLIP: High throughput sequencing of RNA isolated by UV crosslinking immunoprecipitation 
lincRNAs: Long intergenic noncoding RNAs

lncRNA: Long noncoding RNA

miRNA: microRNAs

PAR-CLIP: Photoactivatable-ribonucleosideenhanced crosslinking and immunoprecipitation

PCa: $\quad$ Prostate cancer

PCAT: Prostate cancer associated transcript (nonprotein coding)

piRNA: piwi-interacting RNA

PRC2: $\quad$ Polycomb repressive complex 2

PSA: $\quad$ Prostate-specific antigen

RIP-Seq: RNA immunoprecipitation sequencing

RISC: $\quad$ RNA-induced silencing complex.

\section{Conflict of Interests}

The authors declare that there is no conflict of interests regarding the publication of this paper.

\section{Authors' Contribution}

Julia M. A. Pickl and Doreen Heckmann contributed equally to this work.

\section{Acknowledgments}

This work was supported by the German Federal Ministry of Education and Science in the framework of the Program for Medical Genome Research (FKZ 01KU1001A), the Bruno und Helene Jöster Stiftung, and the German Cancer Consortium (DKTK).

\section{References}

[1] G. K. Wong, D. A. Passey, and J. Yu, "Most of the human genome is transcribed," Genome Research, vol. 11, no. 12, pp. 1975-1977, 2001.

[2] P. Kapranov, S. E. Cawley, J. Drenkow et al., "Large-scale transcriptional activity in chromosomes 21 and 22," Science, vol. 296, no. 5569, pp. 916-919, 2002.

[3] P. Bertone, V. Stolc, T. E. Royce et al., "Global identification of human transcribed sequences with genome tiling arrays," Science, vol. 306, no. 5705, pp. 2242-2246, 2004.

[4] S. Djebali, C. A. Davis, A. Merkel et al., "Landscape of transcription in human cells," Nature, vol. 489, no. 7414, pp. 101-108, 2012.

[5] T. Derrien, R. Johnson, G. Bussotti et al., "The GENCODE v7 catalog of human long noncoding RNAs: analysis of their gene structure, evolution, and expression," Genome Research, vol. 22, no. 9, pp. 1775-1789, 2012.

[6] J. Lu, G. Getz, E. A. Miska et al., "MicroRNA expression profiles classify human cancers," Nature, vol. 435, no. 7043, pp. 834-838, 2005.

[7] Z. Du, T. Fei, R. G. W. Verhaak et al., "Integrative genomic analyses reveal clinically relevant long noncoding RNAs in human cancer," Nature Structural and Molecular Biology, vol. 20, no. 7, pp. 908-913, 2013.

[8] S. Djuranovic, A. Nahvi, and R. Green, "miRNA-mediated gene silencing by translational repression followed by mRNA deadenylation and decay," Science, vol. 336, no. 6078, pp. 237240, 2012.

[9] H. Guo, N. T. Ingolia, J. S. Weissman, and D. P. Bartel, "Mammalian microRNAs predominantly act to decrease target mRNA levels," Nature, vol. 466, no. 7308, pp. 835-840, 2010.

[10] J. E. Braun, E. Huntzinger, M. Fauser, and E. Izaurralde, “GW182 proteins directly recruit cytoplasmic deadenylase complexes to miRNA targets," Molecular Cell, vol. 44, no. 1, pp. 120-133, 2011.

[11] D. P. Bartel, "MicroRNAs: target recognition and regulatory functions," Cell, vol. 136, no. 2, pp. 215-233, 2009.

[12] S. Wach, E. Nolte, J. Szczyrba et al., "MicroRNA profiles of prostate carcinoma detected by multiplatform microRNA screening," International Journal of Cancer, vol. 130, no. 3, pp. 611-621, 2012.

[13] J. Szczyrba, E. Löprich, S. Wach et al., “The microRNA profile of prostate carcinoma obtained by deep sequencing," Molecular Cancer Research, vol. 8, no. 4, pp. 529-538, 2010.

[14] A. W. Tong, P. Fulgham, C. Jay et al., "MicroRNA profile analysis of human prostate cancers," Cancer Gene Therapy, vol. 16, no. 3, pp. 206-216, 2009.

[15] J. C. Brase, M. Johannes, T. Schlomm et al., "Circulating miRNAs are correlated with tumor progression in prostate cancer," International Journal of Cancer, vol. 128, no. 3, pp. 608616, 2011.

[16] M. Hart, E. Nolte, S. Wach et al., "Comparative microRNA profiling of prostate carcinomas with increasing tumor stage by deep sequencing," Molecular Cancer Research, vol. 12, no. 2, pp. 250-263, 2014

[17] A. Schaefer, M. Jung, H. Mollenkopf et al., "Diagnostic and prognostic implications of microRNA profiling in prostate carcinoma," International Journal of Cancer, vol. 126, no. 5, pp. 1166-1176, 2010.

[18] K. Tsuchiyama, H. Ito, M. Taga et al., "Expression of microRNAs associated with Gleason grading system in prostate cancer: miR-182-5p is a useful marker for high grade prostate cancer," Prostate, vol. 73, no. 8, pp. 827-834, 2013.

[19] J. Szczyrba, E. Nolte, S. Wach et al., "Downregulation of Sec23A protein by miRNA-375 in prostate carcinoma," Molecular Cancer Research, vol. 9, no. 6, pp. 791-800, 2011.

[20] M. R. Lang, L. A. Lapierre, M. Frotscher, J. R. Goldenring, and E. W. Knapik, "Secretory COPII coat component Sec23a is essential for craniofacial chondrocyte maturation," Nature Genetics, vol. 38, no. 10, pp. 1198-1203, 2006.

[21] J. Xiao, A. Gong, A. N. Eischeid et al., "MiR-141 modulates androgen receptor transcriptional activity in human prostate cancer cells through targeting the small heterodimer partner protein," Prostate, vol. 72, no. 14, pp. 1514-1522, 2012.

[22] S. Wei, T. A. Dunn, W. B. Isaacs, A. M. de Marzo, and J. Luo, "GOLPH2 and MYO6: putative prostate cancer markers localized to the Golgi apparatus," Prostate, vol. 68, no. 13, pp. 1387-1395, 2008.

[23] T. A. Dunn, S. Chen, D. A. Faith et al., "A novel role of myosin VI in human prostate cancer," The American Journal of Pathology, vol. 169, no. 5, pp. 1843-1854, 2006.

[24] Q. Cao, R. Mani, B. Ateeq et al., "Coordinated regulation of polycomb group complexes through microRNAs in cancer," Cancer Cell, vol. 20, no. 2, pp. 187-199, 2011.

[25] L. V. Williams, D. Veliceasa, E. Vinokour, and O. V. Volpert, "miR-200b inhibits prostate cancer EMT, growth and metastasis," PLoS ONE, vol. 8, no. 12, Article ID e83991, 2013. 
[26] P. A. Gregory, A. G. Bert, E. L. Paterson et al., "The miR200 family and miR-205 regulate epithelial to mesenchymal transition by targeting ZEB1 and SIP1," Nature Cell Biology, vol. 10, no. 5, pp. 593-601, 2008.

[27] Y.-. Liu, J. J. Yin, W. Abou-Kheir et al., "MiR-1 and miR-200 inhibit EMT via Slug-dependent and tumorigenesis via Slugindependent mechanisms," Oncogene, vol. 32, no. 3, pp. 296306, 2013.

[28] M. B. Stope, C. Stender, T. Schubert et al., "Heat-shock protein HSPB1 attenuates microRNA miR-1 expression thereby restoring oncogenic pathways in prostate cancer cells," Anticancer Research, vol. 34, no. 7, pp. 3475-3480, 2014.

[29] S. Majid, A. A. Dar, S. Saini et al., "miRNA-34b inhibits prostate cancer through demethylation, active chromatin modifications, and AKT pathways," Clinical Cancer Research, vol. 19, no. 1, pp. 73-84, 2013.

[30] S. C. Theodore, M. Davis, F. Zhao et al., "MicroRNA profiling of novel African American and Caucasian Prostate Cancer cell lines reveals a reciprocal regulatory relationship of miR-152 and DNA methyltranferase 1," Oncotarget, vol. 5, no. 11, pp. 35123525, 2014.

[31] S. Varambally, J. Yu, B. Laxman et al., "Integrative genomic and proteomic analysis of prostate cancer reveals signatures of metastatic progression," Cancer Cell, vol. 8, no. 5, pp. 393-406, 2005.

[32] L. Poliseno, L. Salmena, J. Zhang, B. Carver, W. J. Haveman, and P. P. Pandolfi, "A coding-independent function of gene and pseudogene mRNAs regulates tumour biology," Nature, vol. 465, no. 7301, pp. 1033-1038, 2010.

[33] J. Schug, L. B. McKenna, G. Walton et al., "Dynamic recruitment of microRNAs to their mRNA targets in the regenerating liver," BMC Genomics, vol. 14, no. 1, article 264, 2013.

[34] G. B. Loeb, A. A. Khan, D. Canner et al., "Transcriptomewide miR-155 binding map reveals widespread noncanonical microRNA targeting," Molecular Cell, vol. 48, no. 5, pp. 760770, 2012.

[35] M. Hafner, M. Landthaler, L. Burger et al., "Transcriptome-wide identification of RNA-binding protein and microRNA target sites by PAR-CLIP," Cell, vol. 141, no. 1, pp. 129-141, 2010.

[36] A. Helwak, G. Kudla, T. Dudnakova, and D. Tollervey, "Mapping the human miRNA interactome by CLASH reveals frequent noncanonical binding," Cell, vol. 153, no. 3, pp. 654-665, 2013.

[37] R. Tang, L. Li, D. Zhu et al., "Mouse miRNA-709 directly regulates miRNA-15a/16-1 biogenesis at the posttranscriptional level in the nucleus: evidence for a microRNA hierarchy system," Cell Research, vol. 22, no. 3, pp. 504-515, 2012.

[38] S. A. Khudayberdiev, F. Zampa, M. Rajman, and G. Schratt, "A comprehensive characterization of the nuclear microRNA repertoire of post-mitotic neurons," Frontiers in Molecular Neuroscience, vol. 6, article 43, 2013.

[39] V. Huang, J. Zheng, Z. Qi et al., "Agol Interacts with RNA polymerase II and binds to the promoters of actively transcribed genes in human cancer cells," PLoS Genetics, vol. 9, no. 9, Article ID e1003821, 2013.

[40] J. Liao, L. Ma, Y. Guo et al., "Deep sequencing of human nuclear and cytoplasmic small RNAS reveals an unexpectedly complex subcellular distribution of mirnas and tRNA 3/ trailers," PLoS ONE, vol. 5, no. 5, Article ID e10563, 2010.

[41] M. Salmanidis, K. Pillman, G. Goodall, and C. Bracken, "Direct transcriptional regulation by nuclear microRNAs," International Journal of Biochemistry \& Cell Biology, 2014.
[42] M. Guttman, I. Amit, M. Garber et al., "Chromatin signature reveals over a thousand highly conserved large non-coding RNAs in mammals," Nature, vol. 458, no. 7235, pp. 223-227, 2009.

[43] G. Dieci, G. Fiorino, M. Castelnuovo, M. Teichmann, and A. Pagano, "The expanding RNA polymerase III transcriptome," Trends in Genetics, vol. 23, no. 12, pp. 614-622, 2007.

[44] P. Kapranov, J. Cheng, S. Dike et al., "RNA maps reveal new RNA classes and a possible function for pervasive transcription," Science, vol. 316, no. 5830, pp. 1484-1488, 2007.

[45] N. T. Ingolia, L. F. Lareau, and J. S. Weissman, "Ribosome profiling of mouse embryonic stem cells reveals the complexity and dynamics of mammalian proteomes," Cell, vol. 147, no. 4, pp. 789-802, 2011.

[46] B. Bánfai, H. Jia, J. Khatun et al., "Long noncoding RNAs are rarely translated in two human cell lines," Genome Research, vol. 22, no. 9, pp. 1646-1657, 2012.

[47] S. Katayama, Y. Tomaru, T. Kasukawa et al., "Antisense transcription in the mammalian transcriptome," Science, vol. 309, no. 5740, pp. 1564-1566, 2005.

[48] M. J. G. Bussemakers, A. ran Bokhoven, G. W. Verhaegh et al., "DD3: a new prostate-specific gene, highly overexpressed in prostate cancer," Cancer Research, vol. 59, no. 23, pp. 5975-5979, 1999.

[49] L. S. Marks, Y. Fradet, I. Lim Deras et al., "PCA3 molecular urine assay for prostate cancer in men undergoing repeat biopsy," Urology, vol. 69, no. 3, pp. 532-535, 2007.

[50] D. Hessels and J. A. Schalken, "The use of PCA3 in the diagnosis of prostate cancer," Nature Reviews Urology, vol. 6, no. 5, pp. 255-261, 2009.

[51] V. Srikantan, Z. Zou, G. Petrovics et al., "PCGEM1, a prostatespecific gene, is overexpressed in prostate cancer," Proceedings of the National Academy of Sciences of the United States of America, vol. 97, no. 22, pp. 12216-12221, 2000.

[52] X. Fu, L. Ravindranath, N. Tran, G. Petrovics, and S. Srivastava, "Regulation of apoptosis by a prostate-specific and prostate cancer-associated noncoding gene, PCGEM1," DNA and Cell Biology, vol. 25, no. 3, pp. 135-141, 2006.

[53] G. Petrovics, W. Zhang, M. Makarem et al., "Elevated expression of PCGEM1, a prostate-specific gene with cell growthpromoting function, is associated with high-risk prostate cancer patients," Oncogene, vol. 23, no. 2, pp. 605-611, 2004.

[54] L. Yang, C. Lin, C. Jin et al., "LncRNA-dependent mechanisms of androgen-receptor-regulated gene activation programs," Nature, vol. 500, no. 7464, pp. 598-602, 2013.

[55] Y. Xue, M. Wang, M. Kang et al., "Association between lncrna PCGEM1 polymorphisms and prostate cancer risk," Prostate Cancer and Prostatic Diseases, vol. 16, no. 2, pp. 139-144, 2013.

[56] J. R. Prensner, M. K. Iyer, O. A. Balbin et al., "Transcriptome sequencing across a prostate cancer cohort identifies PCAT1, an unannotated lincRNA implicated in disease progression," Nature Biotechnology, vol. 29, no. 8, pp. 742-749, 2011.

[57] J. R. Prensner, W. Chen, M. K. Iyer et al., "PCAT-1, a long noncoding RNA, regulates BRCA2 and controls homologous recombination in cancer," Cancer Research, vol. 74, no. 6, pp. 1651-1660, 2014.

[58] S. Chung, H. Nakagawa, M. Uemura et al., "Association of a novel long non-coding RNA in $8 \mathrm{q} 24$ with prostate cancer susceptibility," Cancer Science, vol. 102, no. 1, pp. 245-252, 2011.

[59] A. A. Al Olama, Z. Kote-Jarai, G. G. Giles et al., "Multiple loci on 8q24 associated with prostate cancer susceptibility," Nature Genetics, vol. 41, no. 10, pp. 1058-1060, 2009. 
[60] F. Crea, A. Watahiki, L. Quagliata et al., "Identification of a long non-coding RNA as a novel biomarker and potential therapeutic target for metastatic prostate cancer," Oncotarget, vol. 5, no. 3, pp. 764-774, 2014.

[61] S. Ren, Z. Peng, J. Mao et al., "RNA-seq analysis of prostate cancer in the Chinese population identifies recurrent gene fusions, cancer-associated long noncoding RNAs and aberrant alternative splicings," Cell Research, vol. 22, no. 5, pp. 806-821, 2012.

[62] S. Ren, Y. Liu, W. Xu et al., "Long noncoding RNA MALAT-1 is a new potential therapeutic target for castration resistant prostate cancer," Journal of Urology, vol. 190, no. 6, pp. 2278-2287, 2013.

[63] K. Takayama, K. Horie-Inoue, S. Katayama et al., "Androgenresponsive long noncoding RNA CTBP1-AS promotes prostate cancer," EMBO Journal, vol. 32, no. 12, pp. 1665-1680, 2013.

[64] Z. Cui, S. Ren, J. Lu et al., "The prostate cancer-up-regulated long noncoding RNA PlncRNA-1 modulates apoptosis and proliferation through reciprocal regulation of androgen receptor," Urologic Oncology: Seminars and Original Investigations, vol. 31, no. 7, pp. 1117-1123, 2013.

[65] R. Malik, L. Patel, and J. R. Prensner, "The lncRNA PCAT29 inhibits oncogenic phenotypes in prostate cancer," Molecular Cancer Research, vol. 12, no. 8, pp. 1081-1087, 2014.

[66] J. R. Prensner, A. Sahu, M. K. Iyer et al., "The IncRNAs PCGEM1 and PRNCR1 are not implicated in castration resistant prostate cancer," Oncotarget, vol. 5, no. 6, pp. 1434-1438, 2014.

[67] J. A. Klomp and K. A. Furge, "Genome-wide matching of genes to cellular roles using guilt-by-association models derived from single sample analysis," BMC Research Notes, vol. 5, p. 370, 2012.

[68] C. Chu, K. Qu, F. Zhong, S. Artandi, and H. Chang, "Genomic maps of long noncoding RNA occupancy reveal principles of RNA-chromatin interactions," Molecular Cell, vol. 44, no. 4, pp. 667-678, 2011.

[69] M. D. Simon, C. I. Wang, P. V. Kharchenko et al., "The genomic binding sites of a noncoding RNA," Proceedings of the National Academy of Sciences of the United States of America, vol. 108, no. 51, pp. 20497-20502, 2011.

[70] A. M. Khalil, M. Guttman, M. Huarte et al., "Many human large intergenic noncoding RNAs associate with chromatinmodifying complexes and affect gene expression," Proceedings of the National Academy of Sciences of the United States of America, vol. 106, no. 28, pp. 11667-11672, 2009.

[71] J. Zhao, T. K. Ohsumi, J. T. Kung et al., "Genome-wide identification of polycomb-associated RNAs by RIP-seq," Molecular Cell, vol. 40, no. 6, pp. 939-953, 2010.

[72] K. L. Yap, S. Li, A. M. Muñoz-Cabello et al., "Molecular interplay of the noncoding RNA ANRIL and methylated histone H3 lysine 27 by polycomb CBX7 in transcriptional silencing of INK4a," Molecular Cell, vol. 38, no. 5, pp. 662-674, 2010.

[73] W. Yu, D. Gius, P. Onyango et al., "Epigenetic silencing of tumour suppressor gene p15 by its antisense RNA," Nature, vol. 451, no. 7175, pp. 202-206, 2008.

[74] J. R. Prensner, M. K. Iyer, A. Sahu et al., "The long noncoding RNA SChLAP1 promotes aggressive prostate cancer and antagonizes the SWI/SNF complex," Nature Genetics, vol. 45, no. 11, pp. 1392-1398, 2013.

[75] P. Perot, V. Cheynet, M. Decaussin-Petrucci et al., "Microarraybased identification of individual HERV loci expression: application to biomarker discovery in prostate cancer," Journal of Visualized Experiments, no. 81, Article ID e50713, 2013.
[76] J. H. Li, S. Liu, H. Zhou, L. H. Qu, and J. H. Yang, "StarBase v2.0: decoding miRNA-ceRNA, miRNA-ncRNA and protein-RNA interaction networks from large-scale CLIP-Seq data," Nucleic Acids Research, vol. 42, no. 1, pp. D92-D97, 2014.

[77] C. Carrieri, L. Cimatti, M. Biagioli et al., "Long non-coding antisense RNA controls Uchll translation through an embedded SINEB2 repeat," Nature, vol. 491, no. 7424, pp. 454-457, 2012.

[78] C. Gong and L. E. Maquat, "LncRNAs transactivate STAU1mediated mRNA decay by duplexing with $3^{\prime}$ UTRs via Alu eleme," Nature, vol. 470, no. 7333, pp. 284-288, 2011.

[79] T. B. Hansen, T. I. Jensen, B. H. Clausen et al., "Natural RNA circles function as efficient microRNA sponges," Nature, vol. 495, no. 7441, pp. 384-388, 2013.

[80] S. Memczak, M. Jens, A. Elefsinioti et al., "Circular RNAs are a large class of animal RNAs with regulatory potency," Nature, vol. 495, no. 7441, pp. 333-338, 2013.

[81] G. Wang, A. Lunardi, J. Zhang et al., "Zbtb7a suppresses prostate cancer through repression of a Sox9-dependent pathway for cellular senescence bypass and tumor invasion," Nature Genetics, vol. 45, no. 7, pp. 739-746, 2013.

[82] E. Heitzer, P. Ulz, J. Belic et al., "Tumor-associated copy number changes in the circulation of patients with prostate cancer identified through whole-genome sequencing," Genome Medicine, vol. 5, no. 4, article 30, 2013.

[83] Z. H. Chen, G. L. Zhang, H. R. Li et al., "A panel of five circulating microRNAs as potential biomarkers for prostate cancer," Prostate, vol. 72, no. 13, pp. 1443-1452, 2012.

[84] F. Moltzahn, A. B. Olshen, L. Baehner et al., "Microfluidicbased multiplex qRT-PCR identifies diagnostic and prognostic microRNA signatures in the sera of prostate cancer patients," Cancer Research, vol. 71, no. 2, pp. 550-560, 2011.

[85] R. Mahn, L. C. Heukamp, S. Rogenhofer, A. Von Ruecker, S. C. Müller, and J. Ellinger, "Circulating microRNAs (miRNA) in serum of patients with prostate cancer," Urology, vol. 77, no. 5, pp. 1265.e9-1265.e16, 2011.

[86] R. J. Bryant, T. Pawlowski, J. W. F. Catto et al., "Changes in circulating microRNA levels associated with prostate cancer," British Journal of Cancer, vol. 106, no. 4, pp. 768-774, 2012.

[87] F. Y. Agaoglu, M. Kovancilar, Y. Dizdar et al., "Investigation of miR-21, miR-141, and miR-221 in blood circulation of patients with prostate cancer," Tumor Biology, vol. 32, no. 3, pp. 583-588, 2011.

[88] L. A. Selth, S. L. Townley, A. G. Bert et al., "Circulating microRNAs predict biochemical recurrence in prostate cancer patients," British Journal of Cancer, vol. 109, no. 3, pp. 641-650, 2013.

[89] H.-L. Zhang, L.-F. Yang, Y. Zhu et al., "Serum miRNA-21: elevated levels in patients with metastatic hormone-refractory prostate cancer and potential predictive factor for the efficacy of docetaxel-based chemotherapy," Prostate, vol. 71, no. 3, pp. 326-331, 2011.

[90] D. Olmos, D. Brewer, J. Clark et al., "Prognostic value of blood mRNA expression signatures in castration-resistant prostate cancer: a prospective, two-stage study," The Lancet Oncology, vol. 13, no. 11, pp. 1114-1124, 2012.

[91] R. W. Ross, M. D. Galsky, H. I. Scher et al., "A wholeblood RNA transcript-based prognostic model in men with castration-resistant prostate cancer: a prospective study," The Lancet Oncology, vol. 13, no. 11, pp. 1105-1113, 2012.

[92] A. F. Neves, J. D. D. Dias-Oliveira, T. G. Araújo, K. Marangoni, and L. R. Goulart, "Prostate cancer antigen 3 (PCA3) RNA 
detection in blood and tissue samples for prostate cancer diagnosis," Clinical Chemistry and Laboratory Medicine, vol. 51, no. 4, pp. 881-887, 2013.

[93] S. A. Tomlins, S. M. J. Aubin, J. Siddiqui et al., "Urine TMPRSS2:ERG fusion transcript stratifies prostate cancer risk in men with elevated serum PSA," Science Translational Medicine, vol. 3, no. 94, Article ID 94ra72, 2011.

[94] D. Cao, D. Ye, H. Zhang, Y. Zhu, Y. Wang, and X. Yao, "A multiplex model of combining gene-based, protein-based, and metabolite-based with positive and negative markers in urine for the early diagnosis of prostate cancer," Prostate, vol. 71, no. 7, pp. 700-710, 2011.

[95] M. Mittelbrunn, C. Gutiérrez-Vázquez, C. Villarroya-Beltri et al., "Unidirectional transfer of microRNA-loaded exosomes from T cells to antigen-presenting cells," Nature Communications, vol. 2, no. 1, article 282, 2011.

[96] N. P. Hessvik, S. Phuyal, A. Brech, K. Sandvig, and A. Llorente, "Profiling of microRNAs in exosomes released from PC-3 prostate cancer cells," Biochimica et Biophysica Acta, vol. 1819, no. 11-12, pp. 1154-1163, 2012.

[97] M. Morello, V. R. Minciacchi, P. de Candia et al., "Large oncosomes mediate intercellular transfer of functional microRNA," Cell Cycle, vol. 12, no. 22, pp. 3526-3536, 2013.

[98] J. Nilsson, J. Skog, A. Nordstrand et al., "Prostate cancer-derived urine exosomes: a novel approach to biomarkers for prostate cancer," British Journal of Cancer, vol. 100, no. 10, pp. 1603-1607, 2009.

[99] K. Gabriel, A. Ingram, R. Austin et al., "Regulation of the tumor suppressor PTEN through exosomes: a diagnostic potential for prostate cancer," PLoS ONE, vol. 8, no. 7, Article ID e70047, 2013.

[100] J. C. Gross, V. Chaudhary, K. Bartscherer, and M. Boutros, "Active Wnt proteins are secreted on exosomes," Nature Cell Biology, vol. 14, no. 10, pp. 1036-1045, 2012.

[101] C. Liu, K. Kelnar, A. V. Vlassov, D. Brown, J. Wang, and D. G. Tang, "Distinct microRNA expression profiles in prostate cancer stem/progenitor cells and tumor-suppressive functions of let-7," Cancer Research, vol. 72, no. 13, pp. 3393-3405, 2012.

[102] N. Nadiminty, R. Tummala, W. Lou et al., "MicroRNA let-7c is downregulated in prostate cancer and suppresses prostate cancer growth," PLoS ONE, vol. 7, no. 3, Article ID e32832, 2012.

[103] M. Jin, T. Zhang, and C. Liu, "miRNA-128 suppresses prostate cancer by inhibiting BMI-1 to inhibit tumor-initiating cells," Cancer Research, vol. 74, no. 15, pp. 4183-4195, 2014.

[104] Y. Qu, X. Huang, Z. Li et al., "miR-199a-3p inhibits aurora kinase $\mathrm{A}$ and attenuates prostate cancer growth: new avenue for prostate cancer treatment," The American Journal of Pathology, vol. 184, no. 5, pp. 1541-1549, 2014.

[105] F. Takeshita, L. Patrawala, M. Osaki et al., "Systemic delivery of synthetic microRNA-16 inhibits the growth of metastatic prostate tumors via downregulation of multiple cell-cycle genes," Molecular Therapy, vol. 18, no. 1, pp. 181-187, 2010.

[106] X. Fu, Z. Meng, W. Liang et al., "miR-26a enhances miRNA biogenesis by targeting Lin28B and Zcchcll to suppress tumor growth and metastasis," Oncogene, 2013.

[107] C. Liu, K. Kelnar, B. Liu et al., "The microRNA miR-34a inhibits prostate cancer stem cells and metastasis by directly repressing CD44," Nature Medicine, vol. 17, no. 2, pp. 211-216, 2011.

[108] K. Kojima, Y. Fujita, Y. Nozawa, T. Deguchi, and M. Ito, "MiR$34 \mathrm{a}$ attenuates paclitaxel-resistance of hormone-refractory prostate cancer PC3 cells through direct and indirect mechanisms," Prostate, vol. 70, no. 14, pp. 1501-1512, 2010.
[109] C.-J. Kao, A. Martiniez, X.-B. Shi et al., "miR-30 as a tumor suppressor connects EGF/Src signal to ERG and EMT," Oncogene, vol. 33, no. 19, pp. 2495-2503, 2014.

[110] N. Mercatelli, V. Coppola, D. Bonci et al., "The inhibition of the highly expressed mir-221 and mir-222 impairs the growth of prostate carcinoma xenografts in mice," PLOS ONE, vol. 3, no. 12, Article ID e4029, 2008. 


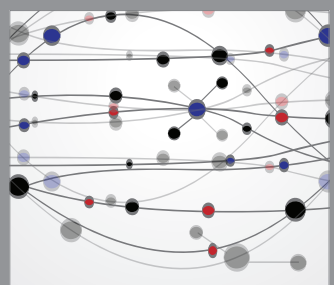

The Scientific World Journal
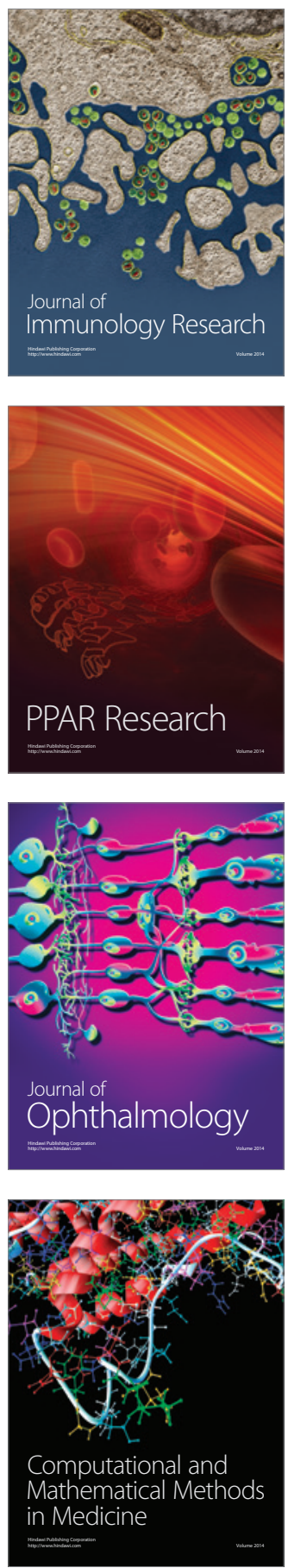

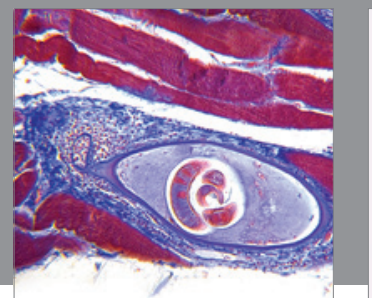

Gastroenterology

Research and Practice
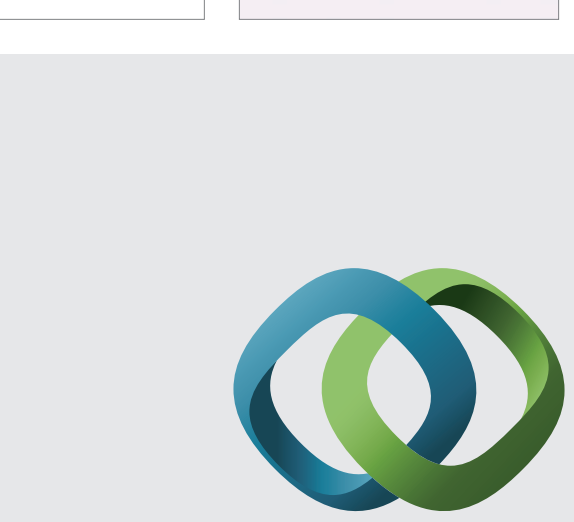

\section{Hindawi}

Submit your manuscripts at

http://www.hindawi.com
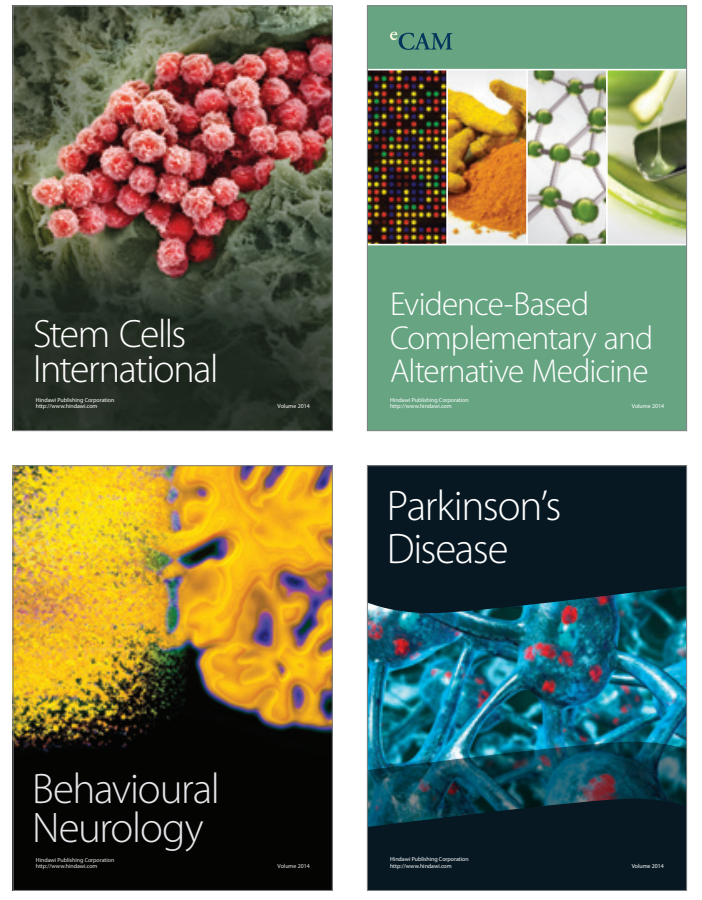
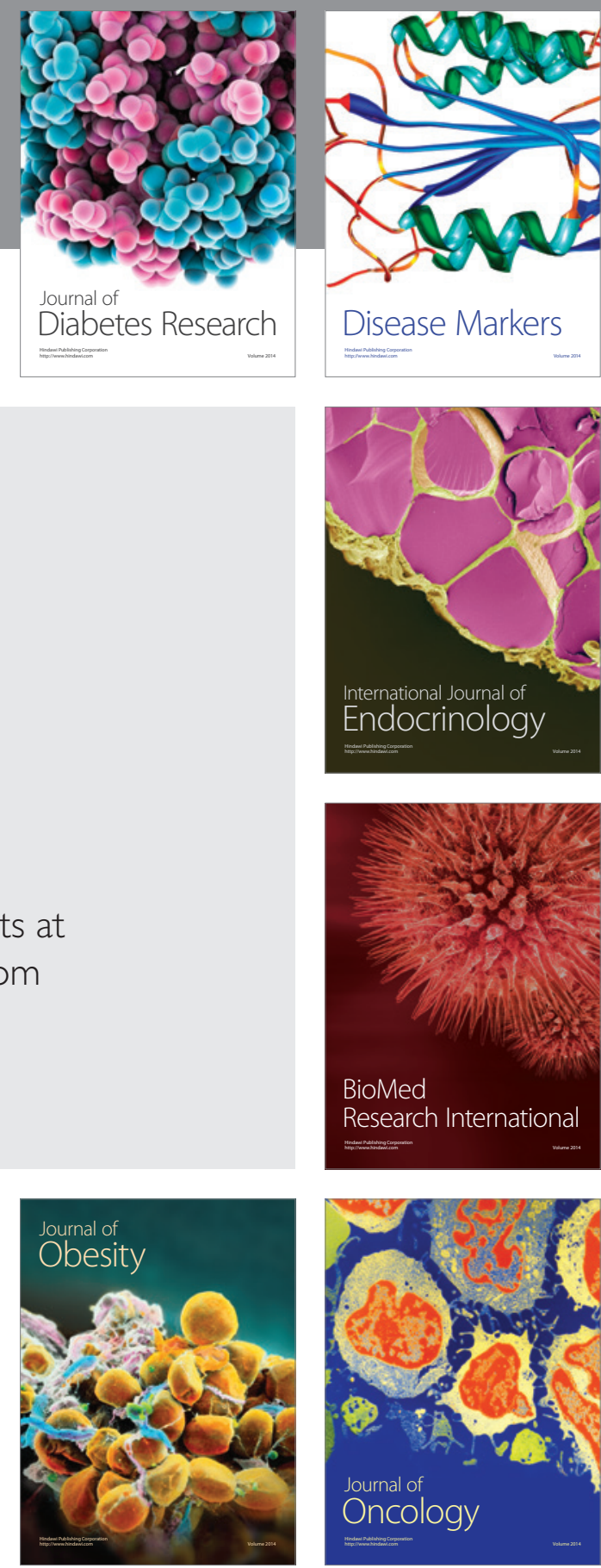

Disease Markers
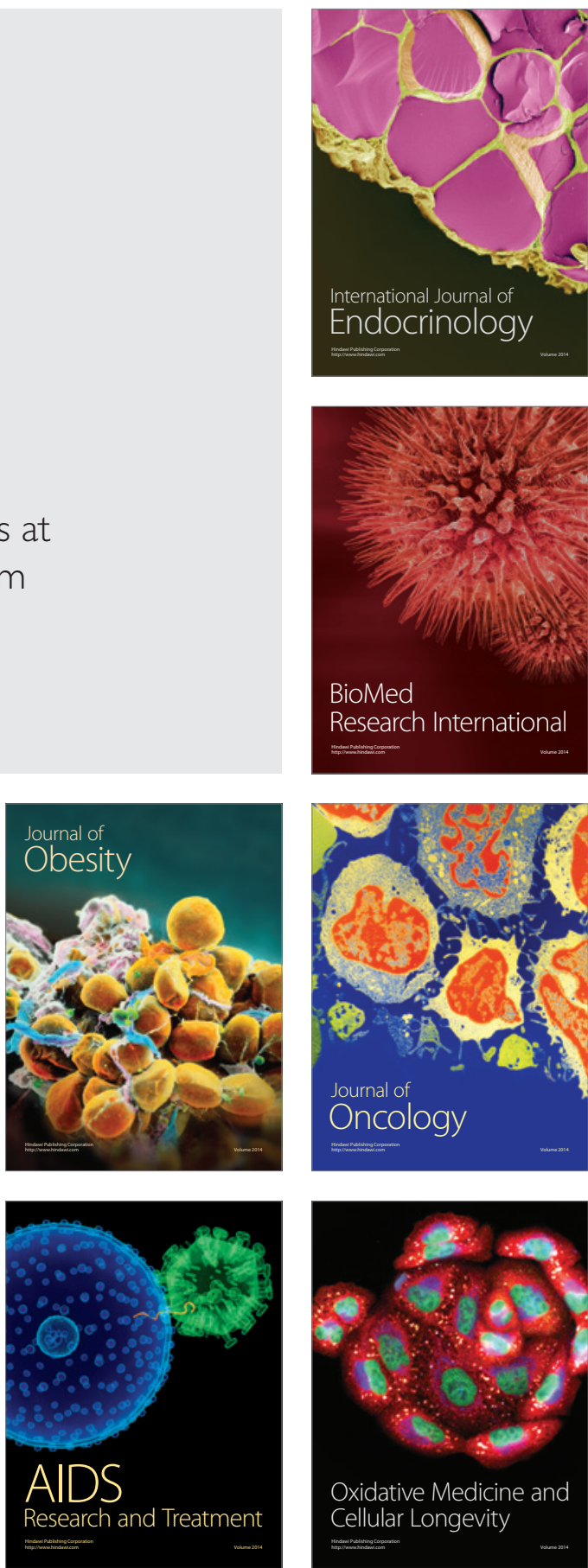